\title{
MARCOS INTERPRETATIVOS DA HISTÓRIA DA AVALIAÇÃO E SUA EXPRESSÃO NO SENAC-SÃO PAULO
}

\author{
Sonia Regina Giusti* \\ Jairo de Araújo Lopes**
}

Recebido em: 18/06/07

Avaliado em: 20/09/07

\footnotetext{
${ }^{*}$ Mestre em Educação pela PUCCAMP. Coord. Técnica do SENAC-São Paulo. E-mail: sgiusti@sp.senac.br

* Dr. em Educação. Prof. do Programa de Pós-Graduação e Coord. de Licenciatura da PUCCAMP.

E-mail: jairo@dglnet.com.br
}

Resumo: O presente trabalho relaciona os principais marcos da avaliação da aprendizagem propostos pela legislação brasileira de 1950 a 1996 e sua incorporação na educação profissional no âmbito do SENAC-São Paulo. Os resultados indicam avanços no sentido de uma concepção tecnicista de avaliação cuja investigação do aproveitamento do aluno está centrada no saber fazer e no final de uma etapa de estudos para uma concepção formativa, cuja investigação está centrada no saber ser, saber fazer, saber conviver e durante o processo de ensino aprendizagem.

Palavras Chave: Avaliação da aprendizagem; Educação profissional; Avaliação formativa.

The evaluation of learning in Brazilian

higher education and its expression at Senac-São Paulo

Abstract: This work lists the main aspects of the evaluation of learning as proposed by the Brazilian legislation from 1950 to 1996 and its incorporation in professional education as seen at SENAC-São Paulo. The results indicate advances from a technicalist conception of evaluation, in which the students performance is assessed at the end of a study stage and based on knowing how to do, towards a formative conception, during the process of teaching and learning and centered in knowing how to be, how to do and how to behave.

Key Words: evaluation of learning; professional education; formative evaluation.

Este artigo sintetiza e discute os principais marcos da avaliação da aprendizagem brasileira relacionando-os à trajetória da avaliação na educação profissional no âmbito do SENAC-São Paulo. 
É parte integrante da dissertação de mestrado da autora, intitulada "Avaliação da aprendizagem na educação profissional em saúde" concluída em Junho/07 na PUC-Campinas.

Delimitamos, para esse estudo, o período de 1950 a 1996, que inclui o momento de criação da instituição e, descrevemos brevemente, as propostas de avaliação da aprendizagem que permearam a educação brasileira e como foram incorporadas pela instituição.

Veremos que a trajetória da avaliação da aprendizagem na educação profissional, no âmbito do Senac-São Paulo, vai de um continuum, inicialmente marcado por medir o aproveitamento do aluno através de notas e provas no final de determinados períodos de estudos, numa proposta de qualificação da mão de obra, ao desafio de avaliar competências profissionais a partir de uma abordagem formativa, cuja ênfase se dá na verificação do aproveitamento durante o processo de ensino-aprendizagem para que se possa melhor regular esse mesmo processo com vistas a garantir a aprendizagem do aluno.

Para retomada do movimento teórico da avaliação da aprendizagem brasileira no período citado anteriormente, foram considerados como referenciais os trabalhos de Sandra M. Z.L. Sousa para as décadas de 30 a 80 e Elza S.S. Barreto para a década de 90.

Para retomada dos caminhos da avaliação no âmbito do SENAC-São Paulo, foram utilizados os regimentos escolares do período em referência.

Em 1942, com a promulgação da Lei Orgânica do Ensino Secundário conhecida como Reforma Capanema, o termo avaliação aparecia como um procedimento de mensuração, onde os resultados de exercícios e exames eram obtidos por meio de notas, que se graduaram de zero a dez.

Não se distinguia avaliação e medida, ambos os termos traduziam a idéia de uma representação quantificada daquilo que o aluno aprendeu. As notas eram métricas através das quais o professor deveria representar o quanto o aluno sabe de determinado conteúdo. Dessa forma, era possível classificá-los de acordo com as médias estabelecidas para aprovação à etapa seguinte.

Essa concepção de avaliação como medida ganhou relevância na década de 30, a partir da adoção dos testes padronizados para medir o desempenho dos alunos tendo em vista objetivos curriculares.

Nos regimentos escolares da década de 50 do SENAC-São Paulo, período em que a instituição foi criada, encontramos a mesma concepção de avaliação como atribuição de notas e função classificatória: "a média 
MARCOS INTERPRETATIVOS DA HISTÓRIA DA AVALIAÇÃO E SUA EXPRESSÃO NO SENAC-SÃO PAULO

aritmética das notas de cada mês, em uma disciplina, será a nota anual de exercícios dessa disciplina." 1

A avaliação do aproveitamento do aluno era medida de acordo com as notas obtidas em cada disciplina, e resultava numa média final para que o mesmo fosse aprovado ou não na referida disciplina. Para aprovação eram consideradas as notas obtidas numa disciplina e média final, não sendo considerados outros fatores que pudessem interferir na obtenção da nota pelo aluno, além daquele momento específico da realização das provas.

$\mathrm{O}$ mesmo procedimento se aplicava às médias finais, compostas pelas notas obtidas, somadas e divididas no término de um processo. Representavam uma relação matemática onde uma nota melhor, num dado mês, podia compensar uma nota mais baixa noutro, mas no final obtinha-se a média para aprovação, o que não significava, necessariamente, apreensão dos conhecimentos mínimos necessários previstos para determinada etapa de estudo.

Embora fossem previstas provas parciais e finais durante o ano, verificava-se que a medição do aproveitamento que se realizava em etapas poderia ser entendida como um processo de avaliação, mas no sentido apenas de mensuração, e não de retroalimentação, com vistas à aprendizagem do aluno.

Na década de 1960, a Lei 4.024/61 define as diretrizes e bases para a educação nacional e no que diz respeito à avaliação não se encontram textos específicos sobre o assunto, levando a crer uma possível tentativa de imprimir caráter mais descentralizador à organização de ensino.

Recorrendo-se a outros documentos que tratam do assunto, como os Pareceres do Conselho Federal de Educação, a avaliação aparece como procedimento para julgar o aproveitamento do aluno mediante suas mudanças de comportamento frente a um determinado grau estabelecido pelo professor e não mais apenas como procedimento de mensuração, como constava na legislação anterior.

Destaca-se também o avanço quanto a considerações no processo de avaliação de variáveis que pudessem interferir na nota final do aluno como sugestões de possibilidades do uso de outros instrumentos para avaliar o aluno de provas e exames.

Quanto aos caminhos que a avaliação percorreu na mesma década de sessenta no SENAC-São Paulo, verificamos os regimentos da instituição

1 Art. 28 Regimento das escolas comerciais $\operatorname{SENAC~(1962,~p.~15)~}$ 
de 1962 a 1970, nos quais destacamos a manutenção de alguns procedimentos de avaliação do aproveitamento da década anterior e algumas modificações que tentamos relacionar com as referenciadas na Lei 4024/61.

A avaliação do aproveitamento do aluno continuou a ser feita através de provas e exames no decorrer do ano, com a obrigatoriedade de um exame final, independente das médias atingidas, para sua promoção como na década anterior:

Para atribuição de nota será adotada a escala de zero (0) a dez (10), permitida a graduação de meio ponto excetuados os meses em que se realizam provas parciais, será dada, nos demais, pelo respectivo professor, em cada disciplina e a cada aluno, uma nota resultante de cada avaliação do seu aproveitamento, verificado por meio de exercícios variados ${ }^{2}$

A escala de notas e a atribuição de notas a partir de exercícios variados, surgiram nessa década e, podem evidenciar uma relação como procedimento de medida das mudanças de comportamento referenciadas na Lei 4024/61, citadas por Sousa (1986), como fator de identificar um grau de satisfatoriedade no desempenho do aluno.

O grau de satisfatoriedade destacado pela autora relaciona-se com uma preocupação em considerar seu desempenho no decorrer do ano letivo para decidir-se sobre a condição de prosseguimento ou não do aluno na série subseqüente.

Avaliação também é referida como processo, e a variedade de instrumentos adotados como forma de avaliar o aluno revela a preocupação com a aprendizagem e com a possibilidade de melhor verificar seu rendimento: "a nota bimestral será resultante das notas decorrentes de exercícios, arguições, tarefas e trabalhos práticos a que serão submetidos os alunos durante o bimestre 3 ".

Podemos considerar como fator de mudanças na concepção, quanto à forma de avaliar o aluno, o avanço na concepção de avaliar como medida para o de avaliar dentro de um padrão de desejabilidade a que o professor deverá considerar as mudanças de comportamento do aluno ocorridas no ano.

A Lei 5692/71, fixou diretrizes para o então primeiro e segundo graus, e instituiu a profissionalização universal e compulsória para o ensino secundário equiparando curso secundário e técnico. A lei apresentava consi-

2 Art. 28 Regimento das escolas comerciais SENAC (1962)

3 Art. 30 Regimentos das escolas comerciais SENAC (1962) 
MARCOS INTERPRETATIVOS DA HISTÓRIA DA AVALIAÇÃO E SUA EXPRESSÃO NO SENAC-SÃO PAULO

derações genéricas sobre avaliação do aproveitamento do aluno, e nas legislações do Estado de São Paulo, encontra-se avaliação do aproveitamento enquanto resultante das diferentes experiências de aprendizagem com estreita ligação entre os sistemas de promoção e recuperação do aluno.

Avaliação aparecia definida como processo de verificar se, e de que forma, os objetivos propostos foram atingidos, como esclarece Sousa (1986, p. 60):

Esta definição complementa a apresentação na legislação anterior, explicitando que os critérios de julgamento do desempenho do aluno estão expressos nos objetivos educacionais definidos. Tem-se, então, que a avaliação não se caracteriza apenas por um procedimento de mensuração, ou seja, dimensionamento de modo preciso (numérico) do desempenho do aluno, mas, sim, por uma atribuição de valor quanto ao grau de desejabilidade do desempenho apresentado.

Este processo está inserido no sistema de avaliação que compreende, além da avaliação do aluno, a promoção e a recuperação da aprendizagem.

Cabe ressaltar que, nesta legislação, a função de avaliar como retroalimentação do processo de tomada de decisões é destacada no texto pela autora: "A avaliação é vista como um procedimento que fornece elementos que devem ser considerados, analisados, ponderados, tendo em vista o aperfeiçoamento das condições de aprendizagem.” (p. 61).

No entanto, a exigência de um exame final, sob pena de não ser completado o processo de avaliação do aproveitamento escolar, aparece como uma contradição, pois significa um engessamento do processo.

Avanços progressivos são definidos no Parecer n. 360/74 do Conselho Federal de Educação ${ }^{4}$ como possibilidades para o aluno caminhar de acordo com suas capacidades mas sua aplicabilidade como processo de acompanhamento e verificação contínua e cumulativa da aprendizagem demanda várias condições para serem implantadas, o que requer uma nova configuração do sistema escolar, em regime não seriado, cuja função da avaliação não seja classificatória e, principalmente, uma grande reflexão e ação sobre o tema na formação inicial e continuada do professor.

4 O Parecer $n^{\circ} 360 / 74$, no item 1, define o sistema de avanços progressivos na trajetória da escola adequando os objetivos educacionais às potencialidades dos alunos. 
Na década de 1970, o SENAC-São Paulo, organiza o trabalho escolar criando o serviço de orientação educacional e profissional, que estabelece as figuras do orientador pedagógico e do orientador educacional e profissional com papéis definidos.

O orientador pedagógico responderia pela execução dos planos de curso e programas de ensino, e o orientador educacional e profissional assistiria aos alunos na sondagem de suas aptidões, ajustamento à família e à comunidade e na escolha da profissão.

Nota-se, com essa reestruturação do trabalho escolar, a possibilidade para um acompanhamento do desempenho do aluno e de outras variáveis que pudessem interferir no aprendizado.

A avaliação da aprendizagem manteve seu caráter classificatório, através das notas dadas dentro de determinada escala; no entanto, não encontramos, dentre os documentos analisados, referências ao uso de provas e exames e, sim a atividades, trabalhos escolares.

Certamente, a aplicação das provas continuaram a existir, mas já não se evidenciavam de forma explícita nos textos, como nas décadas anteriores, o que pode ser entendido como diminuição da importância do uso deste instrumento como único para verificação do rendimento do aluno.

Percebe-se maior preocupação com o aproveitamento do aluno durante o processo pelas atribuições do orientador pedagógico que incluiam, entre outras, a guarda de exercícios preparados pelos professores e realizados pelos alunos, e a elaboração de relatórios sobre esse acompanhamento para os estudos de avaliação.

No final da década de 1970, face aos movimentos de redemocratização do país, as pesquisas em programas de pós-graduação revelaram estudos das relações entre educação e Estado capitalista, principalmente influenciadas pelos trabalhos de pensadores franceses como Pierre Bordieu, Baudelot e Establet e Althusser, que evidenciam a escola como reprodutora do modelo de sociedade capitalista.

No balanço das contribuições das teorias critíco-reprodutivistas, temos ganhos e perdas nas pesquisas educacionais. Ao mesmo tempo em que se revelam conexões entre educação e esferas ideológicas, política e econômica da sociedade, emerge certo imobilismo no que tange à luta por uma sociedade mais democrática, já que as denúncias não vêm acompanhadas de propostas de mudanças.

Os anos 80 do século XX retratavam o processo de transição democrática na sociedade brasileira e o movimento de revalorização da escola, 
MARCOS INTERPRETATIVOS DA HISTÓRIA DA AVALIAÇÃO E SUA EXPRESSÃO NO SENAC-SÃO PAULO

reconhecida tanto como espaço de reprodução cultural e econômica como o de contestação, por um rompimento com uma visão monolítica de Estado, que atua apenas como reprodutor das classes dominantes da sociedade, mas também como representativo das contradições naturalmente presentes em qualquer instância social.

A investigação educacional, nessa ótica, ganhou novas perspectivas pautadas na crença de possibilidades de intervenções comprometidas com as camadas populares. A escola passou a ser considerada como um espaço possível de transformação política e construção da democracia.

Influenciadas por esse movimento, as pesquisas educacionais direcionaram-se para entender ao funcionamento interno da escola, evidenciando seus mecanismos, regras, relações, possibilidades e limites. Valorizavam-se as investigações sobre as relações no interior da escola, a elaboração do currículo e suas avaliações.

A partir da segunda metade dos anos 80 , a avaliação da aprendizagem continuou refletindo uma concepção tecnicista e ganhou movimentos de renovação teórica que rompem com uma visão iminentemente técnica da avaliação, passando a ser investigada mais de perto como comenta Sousa (1994, p. 8):

Acredito que esta perspectiva de análise da escola tenha permeado as pesquisas sobre avaliação da aprendizagem desenvolvidas na década de 80. Ou seja, que as investigações tenham possibilitado o conhecimento e compreensão de como tem sido praticada a avaliação escolar, o que tem sido avaliado e para que se faz avaliação, como expressão de movimentos de acomodação e resistência às normas e valores da organização escolar.

Encontramos pela primeira vez, a partir de 1989, nos regimentos escolares pesquisados, uma definição sobre avaliação como um processo contínuo que prevê a mudança do comportamento do aluno no decorrer do processo de ensino-aprendizagem e relacionados aos objetivos propostos.

Outra referência que aparece destacada é a importância dada aos aspectos qualitativos da aprendizagem sobre os quantitativos: "Na avaliação do aproveitamento preponderarão os aspectos qualitativos sobre os quantitativos." 5

5 Art. 40 Regimento das Unidades Operativas do Senac São Paulo (1984) 
Essa explicitação nos documentos educacionais da prevalência pelos aspectos qualitativos para avaliar o aluno parece caracterizar tentativa de ampliar a visão tecnicista, cujo enfoque se dá no controle pelos resultados obtidos a partir de objetivos pré-definidos.

Os registros escolares do desempenho do aluno durante o processo de aprendizagem que começavam a ser realizados pelos orientadores educacionais, permitiriam um histórico do comportamento do aluno que, somados às provas ou outros instrumentos usados, pudessem resultar numa abordagem qualitativa que começava a se delinear na Instituição na busca por maior aprendizagem e participação do aluno.

Outro fator relevante que encontramos foi a substituição das notas e médias, até então adotadas como representação quantificada do aproveitamento do aluno, por menções, com três critérios para classificação dos alunos: Ótimo, Suficiente ou Insuficiente. ${ }^{6}$

Acreditamos que a tentativa de mudar a atribuição de notas por menções e relacioná-las com critérios de aproveitamento, caracteriza uma preocupação em avaliar o aluno de forma a privilegiar aspectos qualitativos em detrimento dos totalmente quantitativos usados anteriormente, através das notas e médias aritméticas. No entanto, não se evidencia o que significam os aspectos qualitativos e como o professor deve proceder para lidar com essa nova proposta.

Ao relacionar os critérios de aprovação aos percentuais de aproveitamento, previstos em cada plano de curso, parece que se estabelece uma tentativa de garantir que haja de fato a aquisição, pelo aluno, de conteúdos mínimos para sua aprovação em determinada habilitação. No entanto, acreditamos que a substituição de notas por menções não alterou a forma de avaliar os alunos, apenas mudou-se a forma de representar o resultado da avaliação pelo professor.

Nesse processo de mudança, o orientador pedagógico passa a ter papel fundamental no desafio de buscar, junto aos professores, ampliar seus olhares para essa nova concepção de educação com ênfase nos aspectos qualitativos e como fazer isso na prática.

Na década de 90 os estudos de Barretto (2001) referem-se a um novo modelo de avaliação qualitativa que vem se delineando, a partir de diferentes vertentes teóricas em contraposição ao paradigma positivista predominante na tradição brasileira:

6 Art. 41 parágrafo único Regimento das Unidades Operativas do SENAC São Paulo (1984) 
MARCOS INTERPRETATIVOS DA HISTÓRIA DA AVALIAÇÃO E SUA EXPRESSÃO NO SENAC-SÃO PAULO

Como paradigma emergente e multirreferenciado, o modelo de avaliação qualitativa remete à própria complexidade do tema "qualidade da educação", destacando a autora como fatores desse novo modelo: ênfase no processo da aprendizagem menos que nos resultados; avaliação dialógica e dialética que possibilite transformação no plano pessoal e social; avaliação diagnóstica e contínua com trocas constantes entre avaliador e avaliado; eixo da avaliação deslocando-se exclusivamente do aluno para as condições de ensino, formação de professores, currículo. (p. 55).

Evidencia, no campo da sociologia, os referenciais habermasianos ${ }^{7}$ como apoio aos autores que propõem um modelo de avaliação emancipatória, acentuando seus aspectos políticos e sociais.

$\mathrm{Na}$ vertente pedagógica, Barretto (2001, p. 56) cita Luckesi ${ }^{8}$ como expoente principal na temática da avaliação da aprendizagem:

Ele advoga a necessidade de qualificar a avaliação, não em razão dela mesma, mas dos fins a que se destina e, mostra que esta, ao conquistar espaço tão destacado nos processos de ensino ao longo do tempo, condicionou a prática pedagógica à pedagogia do exame. Discute ainda a relação entre planejamento, avaliação e projeto pedagógico da escola, reiterando a dimensão política dessas atividades e preconizando um trabalho coletivo em que as decisões sejam compartilhadas por todos os envolvidos.

Ao paradigma da avaliação qualitativa, somam-se também os estudos psicológicos dando ênfase à avaliação formativa, numa perspectiva mais descritiva e menos prescritiva de construção do conhecimento e mecanismos de aprendizagem do aluno. Ressalta-se o caráter diagnóstico da avaliação, a interatividade no processo e a auto-avaliação do aluno.

Na linha defendida por Barretto, verificamos a adoção de determinadas proposições pelo SENAC-São Paulo quanto ao novo paradigma qualitativo. As notas são substituídas por menções e compreendidas nos parâmetros ótimo, bom, suficiente e insuficiente, o que parece evidenciar

7 Jürgen Habermas - filósofo e sociólogo alemão defende a ação comunicativa entre os homens, sujeitos históricos, como superação da razão iluminista que encobre a dominação burguesa na sociedade.

8 Cipriano José Luckesi é professor aposentado, orientador de pós-graduandos e integrante do Gripo de Pesquisa em Educação e Ludicidade da Universidade Federal da Bahia. É um dos nomes de referência em avaliação da aprendizagem escolar. 
tentativa de transpor o aspecto quantitativo relacionado às representações numéricas. Os parâmetros correspondentes à escala em torno de indicadores para as menções compreendidas entre insuficiente e ótimo parecem conferir tentativa na mesma direção, ou seja, de se substituir o caráter meramente quantitativo expresso em números.

Há também articulação entre promoção, recuperação, compensação de ausências e conclusão de cursos. Para o aluno que apresentar frequiência entre 65 e $75 \%$ das aulas dadas será permitido compensar o excesso de faltas e recuperar o aproveitamento com vistas à aprovação.

Embora o percentual de frequiência para aprovação seja $75 \%$, aos alunos que excederam esse limite, até $65 \%$ no máximo, permite-se a compensação de ausências, através de atividades, trabalhos, aulas extras, entre outras, para que se o aluno consiga atingir o patamar mínimo de aproveitamento para a aprovação daqueles conhecimentos necessários para uma determinada etapa de estudo.

Pode-se entender, com esse critério, a busca em garantir que o aproveitamento mínimo para o desempenho daquela profissão aconteça, dentro dos padrões de competência profissional estabelecidos pela Instituição, regulado pelo mercado de trabalho.

A observação sobre a recuperação, no final do processo ensino-aprendizagem, evidencia que, embora se tenha estabelecido a prevalência dos aspectos qualitativos sobre os quantitativos, revela que a recuperação, quando realizada no final do processo ensino-aprendizagem, compromete o aproveitamento no decorrer do desenvolvimento dos conteúdos. Ou seja, numa proposta de avaliação qualitativa, pressupõe-se que o aproveitamento seja verificado no processo e já possibilite as intervenções necessárias para a recuperação do aluno, não fícando apenas para o final. É o que se denomina de avaliação processual.

A partir de 2001, os planos de cursos do SENAC-São Paulo, já estavam adaptados conforme as diretrizes para a educação profissional da LDB/96, na perspectiva do ensino por competências. "Os critérios de avaliação para verificação do desempenho do aluno serão explicitados nos planos de trabalho dos docentes, em congruência com as competências do perfil de conclusão definido em cada plano de curso." $"$

A avaliação passa a ser prevista como procedimentos integradores e estimuladores que garantam aprendizagem com autonomia. A aprendiza-

9 Art 45 Regimento das Unidades SENAC São Paulo (2003) 
MARCOS INTERPRETATIVOS DA HISTÓRIA DA AVALIAÇÃO E SUA EXPRESSÃO NO SENAC-SÃO PAULO

gem é o objetivo da avaliação, portanto toda a produção realizada pelo aluno através de provas, trabalhos práticos, atividades de pesquisas e projetos são considerados como termômetro de seu aproveitamento: "A avaliação da aprendizagem poderá ser realizada através da elaboração e execução de projetos, provas, pesquisas ou outras atividades planejadas para serem desenvolvidas individualmente ou em grupo." 10

As menções adotadas já desde a década anterior para expressar os resultados do processo de avaliação continuam mantidas, mas têm seu critério ampliado, considerando a avaliação de competências atrelada ao perfil de conclusão dos cursos.

Entendemos que, com essa nova configuração do trabalho pedagógico a partir da determinação legal de que os currículos da educação profissional sejam feitos com base em competências, a avaliação também deverá acontecer de maneira cumulativa e contínua, para que se verifique a capacidade do aluno no avanço das competências adquiridas.

As menções expressas da forma acima podem ajudar o professor a caminhar no sentido de avaliar de forma qualitativa, buscando um relacionamento mais próximo com o aluno, estando mais atento às suas dificuldades, indagações, para as intervenções necessárias no processo.

\section{CONSIDERAÇÕES FINAIS}

Como avaliar competências profissionais se trata de uma proposta nova, e somos todos frutos de uma cultura educacional tradicional que acabou acostumando-se às formas tradicionais de avaliação, que pressupõe estudar para as provas e para passar de ano, o desafio na construção do ensino por competências e da avaliação formativa é de todos os atores envolvidos com a educação profissional.

Entendemos que o desafio em avaliar competências profissionais numa abordagem formativa consiste, entre outros, articular teoria e prática, investigando à apreensão pelo aluno de conhecimentos de base, definidos no perfil profissional de conclusão e alinhados às necessidades do mundo atual do trabalho além de considerar possíveis conhecimentos já incorporados pelo aluno no que diz respeito ao exercício daquela profissão.

10 Idem. 
Torná-lo competente a ponto de aumentar suas chances de inserção no mundo do trabalho pressupõe o domínio de conteúdos diretamente ligados ao exercício de determinada profissão e de outros que permitam a ele ampliar seu olhar para além da técnica.

Dessa forma, acreditamos que a instituição vive um novo paradigma na educação profissional com a proposta de práticas pedagógicas por competências e, que a avaliação da aprendizagem numa abordagem formativa onde o diagnóstico do aproveitamento do aluno se dá no processo, seja mais facilmente concretizada já que a própria prática das atividades profissionais exige por si só um acompanhamento no processo de ensino aprendizagem.

\section{REFERÊNCIAS}

BARRETTO, Elba S. de Sá. Avaliação na educação básica nos anos 90, segundo os periódicos acadêmicos. Cadernos de Pesquisa, São Paulo, n. 114, p. 49-88, nov. 2001.

BRASIL. Lei 9.394 de 20 de dezembro de 1996. Estabelece as diretrizes e bases da educação nacional. Brasília: [s.n], 1996.

BRASIL. Diretrizes curriculares nacionais. Educação básica. Brasília: Conselho de Educação, 2001.

SÃO PAULO. SENAC. Regimento das Unidades SENAC. São Paulo: SENAC, 1955/2004.

SOUSA, Sandra Maria Z. L. Avaliação da aprendizagem na escola de $\mathbf{1}^{\circ}$. grau - legislação, teoria e prática. 1986. Dissertação (Mestrado) - Pontifícia Universidade Católica de Campinas, Campinas, SP, 1986.

Avaliação da aprendizagem: natureza e contribuições da pesquisa no Brasil, no período de 1980 a 1990. 1994. Tese (Doutorado) - Universidade de São Paulo, São Paulo, 1994.

Avaliação da Aprendizagem nas pesquisas no Brasil de 1930 a 1980.

Cadernos de Pesquisa, São Paulo, n. 94, p. 43-49, ago. 1995. 